\title{
B13 Rapid and efficient immunization method using popliteal lymph nodes to generate monoclonal antibodies
}

Fernando de Paiva Conte ${ }^{1}$, Milena Mouta Verdan França Carvalho', Alexandre Bezerra Conde Figueiredo ${ }^{1}$, Isabel Maria Alexandre Freire ${ }^{2}$, Fernanda Rimolli de Castro Araujo², Márcia Arissawa ${ }^{1}$

1 Laboratório de Tecnologia de Anticorpos Monoclonais, BioManguinhos, Fundação Oswaldo Cruz, Rio de Janeiro, RJ

2 Laboratório de Experimentação Animal, Bio-Manguinhos, Fundação Oswaldo Cruz, Rio de Janeiro, RJ

Introduction: Monoclonal antibody $(\mathrm{mAb})$ is a remarkable tool in the advancement of research, diagnostic, and therapeutic applications. Its generation can be achieved through hybridoma fusion technique, a traditional method for generating highly specific mAb. Until the moment, diferente hybridoma protocols (e.g. different routes of immunization, antigen concentration and number of immunizations) were published. Previous work from our group demonstrated that mice immunization accounts for more than $30 \%$ (47 days) of the total time of mAb generation using hybridoma technology. It includes 4 immunizations and $\mathrm{B}$ lymphocyte harvesting from mice spleen. The increasingly demand for mAb development at Bio-Manguinhos led us to develop a rapid and efficient immunization methodology to generate IgG mAb within 19 days through intraplantar immunizations and recovery of $B$ lymphocytes from popliteal lymph nodes, reducing time, costs, number of immunizations and the amount of antigen necessary to mAb generation.

Objective: To develop an efficient and faster protocol for generating monoclonal antibody against human alpha $2 \mathrm{~b}$ interferon (hIFNa2b).

Methodology: BALB/c mice ( 6 weeks old; $n=6$ ) were injected at day 0 into the footpad with and emulsion (1:1) containing $25 \mathrm{~mL}$ of purified hIFNa2b $(25 \mu \mathrm{g})$ in a final volume of $50 \mu \mathrm{L}$ with complete Freund's adjuvant. Fifteen days after initial immunization, mice were injected into the footpad with an emulsion (1:1) of purified hIFNa2b $(25 \mu \mathrm{g})$ in a final volume of $50 \mu \mathrm{L}$ with incomplete Freund's adjuvant. Mice IgG serum titration was assayed at day 18 using indirect enzyme-linked immunosorbent assay (ELISA) against hIFNa2b. Mice presenting serum titer absorbance (I: 450nm) 3x higher than the cut-off were euthanized and the popliteal lymph node cells were pooled and fused with nonsecreting SP2/0-Ag14 cell line using $50 \%$ polyethylene glycol (MW 3,000-3,700). Hybridomas were selected in HAT (hypoxanthineaminopterin-thymidin)-containing medium for 15 days and the supernatants from growing hybrids were screened by

ELISA to select positive clones against hIFNa2b. The positive wells were cloned under limiting dilution conditions and re-screened by 
hIFNa2b ELISA. After recloning, the antibody generated from the clone with higher response against hIFNa2b was further characterized.

Results: Eighteen days after the first immunization, all 6 immunized mice showed increased specific immunoglobulin $G$ ( $\lg G)$ serum titer against $h I F N a 2 b$ when compared to sera from nonimmunized mice. The highest serum IgG antibody titer achieved was 24475 . After fusion and HATmedium selection, 181 wells containing hybridomas secreting mAb against hIFNa2b were generated, as confirmed by specific indirect ELISA against hIFNa2b. Among the positive hybridomas generated, we characterized the hybridoma with highest optical density (O.D.) in ELISA.

Conclusion: The protocol of intraplantar immunization associated with the use of popliteal lymph nodes successfully generated murine IgG $\mathrm{mAb}$ against hIFNa2b. This simple approach may become an efficient, easier and faster method of choice for the generation of $\mathrm{mAb}$.

Keywords: Monoclonal Antibody, Hybridoma, Fusion, Immunization 